\title{
Aspectos gerais da Síndrome de Treacher Collins e seus impactos na qualidade de vida: revisão de literatura
}

General aspects of Treacher Collins Syndrome and its impacts on quality of life: literature review Aspectos generales del Síndrome Treacher Collins y sus impactos sobre la calidad de vida: revisión de la literatura

Amanda de Almeida Prazeres MOREIRA

Universidade Estadual da Paraíba, Centro de Ciências, Tecnologia e Saúde, Campus VIII - UEPB, 58233-000 Araruna - PB, Brasil https://orcid.org/0000-0003-1677-6340

Suzie Clara da Silva MARQUES

Universidade Estadual da Paraíba, Centro de Ciências, Tecnologia e Saúde, Campus VIII - UEPB, 58233-000 Araruna - PB, Brasil https://orcid.org/0000-0002-7598-6260 Marina Tavares Costa NóBREGA

Programa de Pós-Graduação em Odontologia, Universidade Estadual da Paraíba, Campus I- UEPB, 58429-500 Campina Grande - PB, Brasil https://orcid.org/0000-0002-8369-0064

\section{Resumo}

A Síndrome de Treacher Collins é um distúrbio de desenvolvimento de herança autossômica dominante, que ocorre devido à mutação do gene TCOF1. O objetivo desta pesquisa foi abordar um panorama geral sobre a Síndrome de Treacher Collins, por intermédio de uma revisão de literatura, destacando os principais sintomas clínicos e suas consequências nas distintas esferas na qualidade de vida do indivíduo acometido. Para isso, realizou-se uma revisão de literatura, embasada na análise e coleta de dados, por meio das plataformas digitais: Sciello, PubMed e Lilacs. Constata-se que a anomalia em estudo possui uma expressividade variável, podendo manifestar alterações respiratórias, mastigatórias, oftalmológicas e auditivas, devido a mutações no primeiro e segundo arco branquial. Esse quadro torna os indivíduos da síndrome mais propensos a desenvolverem problemas psicológicos não só em virtude dos preconceitos sociais existentes, mas também pelo complexo e multiprofissional tratamento no qual devem ser submetidos para melhores condições de vida.

Descritores: Disostose Mandibulofacial; Anormalidades Craniofaciais; Qualidade de Vida.

\section{Abstract}

Treacher Collins Syndrome is an autosomal dominant development disorder that occurs due to TCOF1 gene mutation. The objective of this research was to approach a general overview about Treacher Collins Syndrome, through a literature review, high lighting the main clinical symptoms and their consequences in the affected individual's quality of life in differents cenarios. For this, a literature review was carried out, based on analysis and data collection, through the digital databases: Sciello, PubMed and Lilacs. It turns out that the anomaly under study has a variable expressiveness, being able to manifest alterations respiratory, masticatory, ophthalmological and hearing, due The mutations in the first and second branchial arc. This picture makes individuals with the syndrome more likely to develop psychological problems not only due to the existing social prejudices, but also the complex and multiprofessional treatment in which they should be submitted for better living conditions.

Descriptors: Mandibulofacial Dysostosis; Craniofacial Abnormalities; Quality of Life.

\section{Resumen}

El Síndrome de Treacher Collins es untrastornodeldesarrolloautosómico dominante que ocurredebido a lamutacióndelgen TCOF1. El objetivo de esta investigaciónfue abordar una visión general del Síndrome de Treacher Collins, a través de una revisión de la literatura, destacando losprincipalessíntomas clínicos y sus consecuenciasenlas diferentes esferas de lacalidad de vida del individuo afectado. Para ello, se realizó una revisión de la literatura, basadaenelanálisis y larecopilación de datos, a través de las plataformas digitales: Sciello, PubMed y Lilacs. Resulta que laanomalíaenestudiotiene una expresividadvariable, pudiendo manifestar alteracionesrespiratorio, masticatorio, oftalmológico y audiencia, debidounmutacionesenel primer y segundo arco branquial. Esta foto hace que las personas conel síndrome sean más propensas a desarrollar problemas psicológicos no solo por losprejuiciossociales existentes, sino también por eltratamientocomplejo y multiprofesionalenel que debería ser enviado para mejores condiciones de vida.

Descriptores: Disostosis Mandibulofacial; Anomalías Craneofaciales; Calidad de Vida.

\section{INTRODUÇÃO}

\section{A síndrome de Treacher Collins é uma} anomalia genética autossômica dominante considerada rara, acometendo cerca 1:50.000 nascidos vivos ${ }^{2,3,4}$. Foi descrita, minuciosamente, por E. Treacher Collins no ano de 1900. Posteriormente, os estudos sobre a temática foram aprofundados por Franceschetti e Klein, possibilitando uma descrição mais detalhada sobre as características dessa condição ${ }^{4}$. Desse modo, a síndrome de Treacher Collins (STC) também é denominada de Síndrome de Franceschetti-Zwahlen-Klein, assim como disostose mandibulofacial ${ }^{4}$.

Essa síndrome configura-se como um distúrbio de desenvolvimento craniofacial caracterizada, sobretudo, por alterações nas estruturas provenientes do primeiro e segundo arco branquial ${ }^{1-3}$. Tal alteração pode ser resultado de uma mutação esporádica ou oriunda da linhagem familiar, sendo causada por uma modificação no gene TCOF1 do cromossomo $5 q 32-q 33.1^{4}$. No que se refere aos achados clínicos da STC, observa-se que demonstram uma expressividade variável ${ }^{1,2}$.

Não obstante, como sintomas típicos, destacam-se: Subdesenvolvimento ou ausência dos ossos zigomáticos, subdesenvolvimento da mandíbula, deformidade ou ausência de orelhas, atresiacoanal, inclinação para baixo da fissura palpebral e fenda palatina ${ }^{1,4}$. Além disso, é possível identificar variações oclusais como mordida aberta anterior, além de deslocamento dos nervos, bem como contração dos músculos mentual e orbicular da boca ${ }^{1}$. Verifica-se ainda que as alterações correlacionadas atingem não somente os aspectos biológicos, mas tambémpsicológicos e, consequentemente sociais, uma vez que a aparência do portador 
da condição é diretamente afetada ${ }^{4}$.

Em virtude das suas manifestações sintomáticas, o tratamento dessa condição genética abrange diversos campos da saúde, havendo a necessidade de uma equipe multidisciplinar na assistência aos pacientes acometidos com a STC ${ }^{1,4}$. Entretanto, a amplitude temática não é diretamente proporcional à quantidade de informações disponíveis, sendo necessário maior entendimento sobre a síndrome.

Por conseguinte, este artigo tem como objetivo abordar um panorama geral sobre a Síndrome de Treacher Collins, por intermédio de uma revisão de literatura destacando os principais sintomas clínicos e suas consequências nas distintas esferas na qualidade vida do indivíduo acometido.

MATERIAL E MÉTODO

Tendo em vista tal panorama, realizouse uma revisão de literatura embasada na análise e coleta de dados atráves das plataformas digitais: Sciello, PubMed e Lilacs, utilizando, para achados da temática abordada, palavras chaves - DisostoseMandibulofacial, Anomalia Craniofacial e Qualidade de Vida associadas e pesquisadas em português no DECS (Descritores em Ciências da Saúde). Por meio do metódo descritivo, com o intuito de compreender, interpretar e esclarecer as informações, a revisão foi realizada ultilizandose como critérios de inclusão: artigos em inglês e português de periódicos nacionais e internacionais, publicados entre o período de 2009 - 2019.

REVISÃO DA LITERATURA

A síndrome de Treacher Collins é uma doença genética autossômica dominante causada por uma alteração não somente no gene TCOF1 do cromossomo 5 - responsável pelo desenvolvimento das estruturas faciais mas também pelos genes POLR1C e POLR1D ${ }^{1}$, considerados até então, responsáveis pela alteração fenotípica; entretanto, é válido ressaltar que em alguns pacientes com STC, não há mutações nesses genes ${ }^{7}$. Nesse cenário, tal anomalia pode ser considerada hereditária ou fruto de uma nova mutação (sendo a maior parte dos casos fruto de uma mudança esporádica), caracterizada pela introdução de um códon de parada prematuro, em sua maioria ${ }^{1,8}$. Sendo assim, é uma condição cujo acometimento independe do gênero ou etnia.

Clinicamente, é observada uma variação fenotípica inerente ao portador da anomalia, em virtude das falhas genéticas. Essas alterações anatômicas são expressas de maneira particular em cada indivíduo afetado, configurando uma síndrome de expressividade variável e grande variabilidade sintomática ${ }^{1,2}$. Entretanto, de forma geral, a STC acarreta alterações bilaterais e simétricas, sendo as estruturas comprometidas fruto de uma má formação embrionária do primeiro e segundo arco branquial ${ }^{1-3}$.

A priori, verifica-se que devido à malformação óssea e tecidual, os acometidos pela doença apresentam, sobretudo, dificuldades auditiva, respiratória, mastigatória, oftalmológicas, além de comprometimentos estéticos $^{1-3,8}$. Dentre as manifestações relacionadas à orelha, destaca-se sua malformação ou ausência, denominada microtia ou anotia, respectivamente ${ }^{4}$. Somado a isso, também é possível constatar deformidades no ouvido externo e médio, responsáveis pela condução do som para as terminações nervosas, resultando em um panorama que compromete a capacidade auditiva em razão dos variados graus de hipoplasia do canal auditivo $^{1,2,4}$. Nessa perspectiva, em alguns pacientes, tais alterações são responsáveis por gerar um significativo atraso na fala, uma vez que a condução sonora é prejudicada ${ }^{8}$.

Além disso, é válido ressaltar a hipoplasia do terço médio da face e o hipodesenvolvimento da mandíbula e mento ${ }^{4}$. Esse subdesenvolvimento ósseo interfere, diretamente, na realização das funções vitais, uma vez que a cavidades nasal e faríngea encontram-se rodeadas pela base craniana e maxilar. Nesse contexto, é notável uma compressão da faringe, principalmente na posição da orofaringe, em virtude de uma redução na base e no ângulo do crânio. Dessa forma, os portadores da síndrome apresentam menor distância entre a base posterior do crânio e o piso da via aérea nasal ${ }^{5,11}$.

Tais características são intrínsecas a STC e interferem, diretamente, na função respiratória, visto que a posição retrusa dos ossos da região resultam em um estreitamento do trato respiratório superior ${ }^{4}$. Assim, a obstrução das vias aéreas eleva a probabilidade de insuficiência pulmonar, interferindo, portanto, em toda cadeia respiratória ${ }^{5}$. Como consequência, os ciclos respiratórios requerem maior gasto energético pelo maior esforço muscular empregado nesse mecanismo fisiológico, o que resulta em indivíduos de baixo peso corporal ${ }^{4}$.

A obstrução das vias aéreas torna os indivíduos portadores da STC mais propensos a desenvolverem determinados distúrbios: A Apneia Obstrutiva do Sono (SAOS) em adultos 
provoca uma diminuição da concentração, dores de cabeça, memória prejudicada e depressão; já em crianças causa déficits de crescimento e problemas comportamentais, como agressividade, hiperatividade, além de problemas de socialização. Pode causar, ainda, nesses grupos, hipóxia e hipercapnia intermitente, repetidas variações de pressão intratorácica e despertares episódicos ${ }^{9}$.

Outros distúrbios respiratórios como hipopneias e despertares relacionados ao esforço respiratório podem ser associados aos acometidos com a síndrome de Treacher Collins. Esses episódios de alteração no sono, quando ocorridos de maneira regular, afetam a qualidade de vida dos indivíduos, gerando um quadro de morbidade que afeta o sistema nervoso central das pessoas nessa situação ${ }^{9}$.

Os principais sinais e sintomas que podem se apresentar no complexo maxilomandibular desses indivíduos são:dentes supranumerários impactados na região anterior superior; hipoplasias e alterações no posicionamento dos incisivos centrais superiores; micrognatia; displasia de articulação temporomandibular (ATM); limitação de abertura bucal; desvio da linha média; má oclusão; prognatismo ou retrognatismo mandibular e mordida aberta anterior ${ }^{1}$.

Também é notória a presença de fenda palatina que ocorre em, aproximadamente, um terço dos portadores da STC, não havendo diferença de tempo de reparação entre esses e os indivíduos não portadores da síndrome. No entanto, foi observado que os pacientes com STC podem sofrer de uma maior incidência de formação de fístula após reparação. Somado a isso também é possível observar uma hipoplasia ou aplasia das glândulas salivares, o que resulta em uma reduzida secreção salivar, influenciando na mastigação e deglutição ${ }^{8,9}$.

Como disfunções oftalmológicas podem ocorrer órbitas mal formadas e assimétricas em razão da hipoplasia zigomática, coloboma das pálpebras inferiores e íris, disfunção no sistema lacrimal, estrabismo, ambliopia, cataratas congênitas, erros de refração e perda de visão ${ }^{8}$. Sendo válido ressaltar a expressividade variável da síndrome de Treacher Collins nos seus portadores.

No que se refere aos fatores estéticos, pode-se dizer que além da alteração funcional, esses são responsáveis por gerar problemas sociais ao indivíduo com a síndrome. Tal panorama é fruto dos preconceitos que permeiam a STC o que resulta em ofensas no ambiente escolar, principalmente, mas também em outros locais públicos. Nesse cenário, observa-se que os indivíduos com a síndrome apresentam maior porcentagem de problemas psicológicos, como ansiedade (associada, sobretudo, a uma constante insegurança sobre possíveis reações desagradáveis de outras pessoas) e depressão, em comparação a outras doenças genéticas ${ }^{6,10}$. Essa realidade torna fundamental 0 acompanhamento psicológico aos afetados com a anomalia, não só como uma forma de enfrentar os estigmas da sociedade, mas também o tratamento complexo exigido ${ }^{4}$.

O diagnóstico pode ser estabelecido desde o pré-natal por meio dos achados anatômicos identificados por exames de ultrassonografias, como micrognatia, alterações na orelha, testa inclinada, polihidrâmnio e fenda palpebral antimongolóide ${ }^{2}$. Esse reconhecimento prévio é de extrema importância para realização de um tratamento precoce, uma vez que os portadores da síndrome apresentam dificuldades de ouvir, respirar e mastigar. Tornam-se, portanto, aspectos que devem ser analisados prioritariamente, em função da influência que tais alterações ocasionam na qualidade de vida, visto a eficiência das funcionalidades'. Entretanto, destaca-se que os exames de ultrassom não são capazes de diferenciar tipos semelhantes de disostoses ${ }^{8}$. Passado o período gestacional, essa confirmação da presença da síndrome pode ser feita logo após o nascimento, a partir da avaliação da saturação de oxigênio (desaturações são comuns em decúbito dorsal) ${ }^{8}$.

O tratamento para a síndrome de Treacher Collins pode ser dividido em três estágios distintos e consiste, basicamente, em tratamentos cirúrgicos que amenizem, prioritariamente, as desconformidades funcionais ${ }^{3}$ : 0 primeiro engloba desde 0 nascimento até os dois anos de idade e as intervenções buscam atenuar os problemas relacionados à respiração e alimentação através de procedimentos cirúrgicos, como distração osteogênica da mandíbula, correção daatresia dascoanas, queiloplastia, palatoplastia e reconstrução palpebral - se necessário ${ }^{1,3}$.

O segundo estágio atravessa o intervalo de 2 aos 12 anos de idade e busca suavizar as alterações no terço superior da face, por meio da reconstrução malar, auricular, palpebral e mandibular, distração osteogênica da mandíbula (em alguns casos, quando a via aérea é bastante comprometida, essa é realizada de maneira precoce, com o intuito de evitar a realização da traqueostomia), além da lipoenxertia. Além disso, é indicado o início dos cuidados a saúde mental ${ }^{1,3,8}$. Já 0 terceiro 
estágio, compreendido entre os treze os dezoito anos, ocorre o térmico iniciado no momento anterior, já que há o encerramento do crescimento ósseo. Nesse período, é realizado a rinoplastia e cirurgia ortognática ${ }^{1,3}$.

A complexidade das cirurgias pelo qual o paciente é submetido, em ambiente multidisciplinar, impacta, de maneira retilínea, a qualidade de vida desses indivíduos e seus familiares. Visto que, na maioria dos casos, o tratamento tem início na infância e se prolonga até o final do crescimento ósseo craniofacial ${ }^{6}$. No momento, as intervenções para a recuperação e tratamento são baseadas em poucas evidências relatadas por especialistas, através de casos e estudos de corte retrospectivo ${ }^{7}$.

Somado a isso, é imprescindível ressaltar a importância de uma equipe multiprofissional no tratamento da STC, sendo fundamental a participação de oftalmologistas, otorrinolaringologistas, cirurgiões craniofaciais, fonoaudiólogos, nutricionistas, fisioterapeutas, psicólogos e cirurgiões-dentistas ${ }^{1,4}$. Nesse último, torna-se estritamente necessário 0 acompanhamento com ortodontistas, para minimizar os danos na mastigação e, consequentemente, digestão ${ }^{1}$.

CONCLUSÃO

Por conseguinte, nota-se que a síndrome de Treacher Collins afeta as estruturas provenientes do primeiro e segundo arco branquial, acarretando disfunções respiratórias (essas são responsáveis pelo baixo peso corporal dos indivíduos e, em muitos casos, geram distúrbios do sono), mastigatórias (em virtude de uma severa micrognatia, displasias na articulação temporomandibular e má oclusão), auditivas (expressas através de alterações na orelha e no ouvido, que podem resultar em um atraso da linguagem) e oftalmológicas (manifestadas em alterações anatômicas nas órbitas, disfunções no sistema lacrimal, erros de refração e até perda de visão). Tais características físicas provocam problemas psicológicos em razão dos preconceitos sociais e do complexo tratamento necessário.

Dado esse contexto, é de suma importância o diagnóstico prévio, visto que a intervenção precoce influencia, diretamente, nos resultados terapêuticos. Somado a isso, verificase a necessidade dos indivíduos portadores da doença possuírem acesso a um atendimento multiprofissional para suavização das manifestações físicasdessa anomalia. As cirurgias aliadas à constatação precoce da doença são a melhor alternativa para minimização dos danos, propiciando uma melhor qualidade de vida aos acometidos pela mutação.

\section{REFERÊNCIAS}

1. Spezzia S. Repercussões bucais da Síndrome de Treacher Collins: revisão de literatura. J Oral Inv. 2018;7:89-97.

2. Mazetti MPV, Martins DMFS, Gomes PO, Brock RS, Kobata CT, Ferreira JS et al. Distração óssea na disostosemandíbulo-facial: revisão de literatura. Rev Bras Cir Craniomaxilofac. 2009;12:29-33.

3. Yoshida M, Tonello C, Alonso N. Síndrome de Treacher Collins: desafio na otimização do tratamento cirúrgico. Ver Bras Cir Craniomaxilofac. 2012;15:64-8.

4. Lodovichi FF, Oliveira JP, Denadai R, RaposoAmaral CA ,Ghizoni E, Raposo-Amaral CE . Traz a deformidade de orelha impacto negativo na qualidade de vida em indivíduos com síndrome de Treacher Collins? Cienc Saude Colet. 2018;23:4311-18.

5. Max Forte AJ, Berlin NL, Alonso N, Persing JA , Steinbacher DM . Reduced Three Dimensional Nasal Airway Volume in Treacher Collins Syndrome and Its Association with Craniofacial Morphology. Plast Reconstr Surg. 2015;135:885-94.

6. de Oliveira JP, Lodovichi FF, Gomes MB, Custódio EM, Denadai R, RaposoAmaral CA et al. Patient-reported quality of life in the highest functioning patients with Treacher Collins Syndrome. J Craniofac Surg. 2018;29:1430-33.

7. Plomp RG, van Lieshout MJ, Joosten KF, Wolvius EB, van der Schroeff MP, Versnel SL, et al. Treacher Collins Syndrome: a systematic review of evidence-based treatment and recommendations. Plast Reconstr Surg Glob Open. 2015;137:191-204.

8. Aljerian A, Gilardino MS. Treacher Collins Syndrome. Clin Plastic Surg.2019;46:197-205.

9. Geirdal AO, Overland B, Heimdal K, Storhaug $\mathrm{K}$, Asten $\mathrm{P}$, Akre $\mathrm{H}$. Association between obstructive sleep apnea and health-related quality of life in individuals affected with Treacher Collins syndrome. Eur Arch Otorhinolaryngol. 2013;270:2879-84.

10. Geirdal AO, Saltnes SS, Storhaug K, Asten P, Nordgarden $\mathrm{H}$, Jensen JL. Living with orofacial conditions: psychological distress and quality of life in adults affected wothTreacher Collins syndrome, cherubism, or oligodontia/ectodermal dysplasia - a comparative study. Qual Life Res.2015;24: 927-35.

11. Ribeiro AA, Smith FJ, Nary Filho $H$, Trindade IEK, Tonello C, Trindade-Suedam IK. ThreeDimensional Upper Airway Assesment in Treacher Collins Syndrome. Cleft Palate Craniofac J. 2020;57:371-77. 


\section{CONFLITO DE INTERESSES}

Os autores declaram não haver conflitos de interesse

\section{AUTOR PARA CORRESPONDÊNCIA}

\section{Suzie Clara da Silva Marques}

Universidade Estadual da Paraíba,Centro de Ciências,

Tecnologia e Saúde, Campus VIII - UEPB,

58233-000 Araruna - PB, Brasil

E-mail: suzieclara08@gmail.com

Submetido em 26/05/2020

Aceito em 16/07/2021 